\title{
LIBERDADE E TERRITORIALIDADE: OS LIMITES DO PODER DO ESTADO E DA SOCIEDADE EM CONSTANT, MILL E TOCQUEVILLE
}

\author{
Rosângela Almeida Chaves ${ }^{1}$
}

Resumo: Benjamin Constant, John Stuart Mill e Alexis de Tocqueville foram três grandes nomes do liberalismo do século XIX, reconhecidos pela relevância de suas reflexões sobre a liberdade. O objetivo do artigo é discutir a concepção de liberdade nestes três autores - com base na relação que eles estabelecem entre liberdade individual e liberdade política e a extensão territorial das comunidades políticas - e os limites do poder do Estado e da sociedade sobre os indivíduos. Para tanto, será confrontada a perspectiva de Constant e Mill, os quais concebem a liberdade nos tempos modernos como sinônimo das liberdades individuais, com a de Tocqueville, cuja concepção de liberdade conjuga a independência individual com a participação política. No que tange à territorialidade, nosso esforço será mostrar que, enquanto para Constant e Mill, a maior extensão dos Estados modernos é um fator que favorece a liberdade individual - em contraposição aos limites estreitos das repúblicas antigas, as quais exerciam um maior controle sobre os cidadãos -, para Tocqueville, é justamente o poder comunal, representado pelos corpos municipais ou comunas, que proporciona aos cidadãos a chance de ter uma maior participação política.

Palavras-chave: liberdade -territorialidade - política - liberalismo.

\section{Introdução}

A proposta do artigo é discutir a concepção de liberdade em três autores alinhados à corrente liberal do século XIX - Benjamin Constant, John Stuart Mill e Alexis de Tocqueville -, tendo como foco a relação que eles estabelecem entre liberdade individual e liberdade política e a extensão territorial das comunidades políticas, com base na análise dos seguintes textos: Da liberdade dos antigos comparada à dos modernos, o célebre discurso de Constant proferido em 1819; o livro Sobre a liberdade, de Mill, e algumas passagens de A democracia na América, de Tocqueville.

Nosso intento é confrontar a posição de Constant e de Mill, para os quais a liberdade nos tempos modernos é sinônimo das liberdades individuais, com a de Tocqueville, cuja concepção de liberdade procura associar a independência individual com a participação política. No que tange à territorialidade, nosso esforço será mostrar que, enquanto para Constant e Mill, a maior extensão dos Estados modernos é um fator que favorece a liberdade individual - em contraposição aos limites estreitos das repúblicas antigas, as quais exerciam um maior controle sobre os cidadãos -,

\footnotetext{
${ }^{1}$ Doutora em Filosofia pela Universidade Federal de Goiás (UFG). E-mail: rosangelachaves13@gmail.com.
} 
para Tocqueville, por seu turno, é justamente o poder comunal, representado pelos corpos municipais ou comunas, que proporciona aos cidadãos a chance de ter uma maior participação política, além de representar um obstáculo à tendência de centralização do poder que o autor enxergava nos Estados modernos e as ameaças que essa centralização poderia representar para a liberdade dos indivíduos.

\section{Liberdade individual e liberdade política}

No célebre discurso que proferiu no Ateneu de Paris em 1819, denominado Da liberdade dos antigos comparada à dos modernos, Benjamin Constant (1767-1830) pergunta à plateia o que um francês, um inglês ou um norte-americano entende por liberdade, para em seguida ele próprio dar a resposta: a liberdade reside no direito de se submeter somente às leis; de não ser preso e condenado arbitrariamente; de exercer o direito de opinião; de escolher livremente uma ocupação profissional; de dispor como se bem quiser de sua propriedade, "e até de abusar dela"; de ir e vir sem precisar de permissão; de poder reunir-se com outros indivíduos, seja para tratar de assuntos de interesse comum, seja com o objetivo de professar um culto, seja para simplesmente "preencher seus dias e suas horas de maneira mais condizente com suas inclinações, com suas fantasias". ${ }^{2}$ Em suma, como Constant sintetiza mais adiante, a liberdade, nos tempos modernos, não é nada mais nada menos do que "o gozo pacífico da independência privada". ${ }^{3}$

É justamente a ênfase na independência pessoal e na vida privada a diferença crucial que Constant enxerga entre a visão de liberdade na época moderna e a dos tempos antigos. No modelo republicano de Roma e de Esparta, conforme ele exemplifica, os cidadãos gozavam de uma ampla soberania no espaço público - deliberavam e decidiam coletivamente sobre a guerra e a paz, os tratados de aliança, as leis que os regiam, as contas públicas, a administração dos magistrados, entre outros assuntos de interesse geral. Mas, embora soberano nas questões públicas, o indivíduo, por estar inteiramente submetido ao todo representado pela coletividade, não tinha praticamente nenhuma autonomia na vida privada. "Os antigos, como diz Condorcet, não tinham nenhuma noção dos direitos individuais. Os homens não eram, por assim dizer, mais que máquinas das quais a lei regulava as molas e dirigia as engrenagens", observa Constant. ${ }^{4}$

\footnotetext{
${ }^{2}$ CONSTANT, De la liberté des anciens comparée à celles des modernes, p. 17-18.

${ }^{3}$ CONSTANT, De La liberté des anciens comparée à celles des modernes, p. 28.

${ }^{4}$ CONSTANT, De La liberté des anciens comparée à celles des modernes, p. 20-21. Entre as repúblicas antigas, Constant faz uma exceção a Atenas. Segundo ele, a cidade-Estado grega é a que mais se aproxima dos tempos modernos, porque seus cidadãos gozavam de mais liberdade individual, algo que ele creditava ao intenso comércio que movimentava Atenas, tornando-a menos rígida em seus costumes e mais aberta aos estrangeiros. No entanto, a predominância do corpo social sobre o indivíduo também prevalecia em Atenas, ressalva Constant (2016, p. 26-27).
} 
Em contrapartida, embora o homem moderno desfrute, segundo ele, de uma ampla independência na vida privada, Constant reconhece que sua soberania, no espaço público, é apenas aparente. Ao passo que os cidadãos das repúblicas antigas estavam dispostos a fazer muitos sacrifícios pela conservação dos seus direitos políticos e de sua parte na administração do Estado tendo em vista que a sua vontade exercia de fato uma influência real nos negócios públicos -, a mesma disposição não é percebida entre os modernos. Em meio à multidão que habita as grandes nações modernas, a vontade dos indivíduos pouco conta por si só, e o exercício dos direitos políticos está longe de proporcionar a mesma satisfação que os antigos experimentavam no seu papel de atores políticos. 5

Para Constant, no entanto, esse é o preço a pagar por um modelo de organização sociopolítica que privilegia a liberdade individual.

[...] pedir aos povos de hoje para sacrificar, como os de antigamente, a totalidade de sua liberdade individual à liberdade política é o meio mais seguro para afastá-los da primeira, com a consequência de que, feito isso, a segunda não tardará a lhe ser arrebatada. ${ }^{6}$

Não é o caso de prescindir da liberdade política, mas de entender que, na modernidade, ela deve ser vista como uma forma de garantia da verdadeira liberdade, na concepção de Constant: a liberdade individual.

Se entre os antigos, quanto mais tempo e energia os cidadãos empregavam no exercício dos seus direitos políticos, mais eles se consideravam livres, na época moderna, o exercício desses direitos deve ocorrer de tal forma que proporcione aos indivíduos mais tempo para cuidar de seus interesses privados.

O objetivo dos antigos era a partilha do poder social entre todos os cidadãos de uma mesma pátria: era isso o que eles denominavam liberdade. O objetivo dos modernos é a segurança dos privilégios privados; e eles chamam liberdade as garantias concedidas pelas instituições a esses privilégios. ${ }^{7}$

Seguindo essa linha de raciocínio, Constant acredita que o melhor modelo político para os tempos modernos é o baseado no sistema representativo. Definido por Constant como uma "procuração dada a um certo número de homens pela massa do povo que deseja ter seus interesses defendidos", o sistema representativo permite aos povos desfrutar da liberdade que "lhes é útil", ou

\footnotetext{
${ }^{5}$ Cf. CONSTANT, De La liberté des anciens comparée à celles des modernes.

6 CONSTANT, De La liberté des anciens comparée à celles des modernes, p. 40-41.

${ }^{7}$ CONSTANT, De La liberté des anciens comparée à celles des modernes, p. 29.
} 
seja, a liberdade privada. A liberdade política dos indivíduos restringir-se-ia, então, ao direito de voto e à vigilância "ativa e constante" sobre os seus representantes. ${ }^{8}$

Benjamin Constant proferiu seu famoso discurso no contexto da Restauração na França, sob o reinado de Luís XVIII, uma monarquia constitucionalista cujo parlamento era eleito pelo voto censitário e que marcou o retorno dos Bourbon ao poder após a derrota de Napoleão em Waterloo, em 1815. Opositor de Napoleão e crítico do que considerava os excessos da Revolução Francesa, Constant argumenta que foi exatamente a tentativa de instituir a liberdade antiga num contexto moderno o grande erro dos revolucionários de 1789. Referindo-se respeitosamente a Rousseau ("evitarei, é claro, juntar-me aos detratores de um grande homem", pondera), ele lastima que o filósofo genebrino e um de seus sucessores, o abade de Mably (este, "mil vezes mais exagerado"), cujas ideias exerceram enorme influência sobre os líderes da Revolução Francesa, tenham tomado a liberdade do corpo social pela liberdade. ${ }^{9}$

Os homens que foram levados pela onda dos acontecimentos a liderar nossa revolução estavam, em consequência da educação que haviam recebido, imbuídos das opiniões antiquadas, e reveladas depois como falsas, que os filósofos de que falei haviam posto em realce. [...] Eles acreditaram que tudo devia ainda ceder à vontade coletiva e que todas as restrições aos direitos individuais seriam largamente compensadas pela participação no poder social. ${ }^{10}$

Para Constant, o poder social que os revolucionários tentaram impor atacava em todos os sentidos a independência individual, sem, contudo, destruir-lhe a necessidade. Foi por essa incapacidade de seus líderes de compreender o valor dessa independência para os homens modernos que o esforço deles em manter o "edifício renovado dos antigos" malogrou. "A independência individual é a primeira das necessidades modernas. Consequentemente, não se deve nunca pedir seu sacrifício para estabelecer a liberdade política", alerta Constant. ${ }^{11}$

Segundo Callot, o liberalismo de Constant eleva o indivíduo como o valor supremo. ${ }^{12}$ No prefácio de Mélanges de litterature et de politique (1829), Constant deixa clara essa visão: “[...] por liberdade eu entendo o triunfo da individualidade, tanto sobre a autoridade que quer governar pelo despotismo como sobre as massas que reclamam o direito de assujeitar a minoria à maioria". ${ }^{13}$ Conforme Merquior, Constant popularizou a ideia da liberdade moderna como um fenômeno

\footnotetext{
${ }^{8}$ CONSTANT, De La liberté des anciens comparée à celles des modernes, p. 45.

${ }^{9}$ CONSTANT, De La liberté des anciens comparée à celles des modernes, p. 31-32.

${ }^{10}$ CONSTANT, De La liberté des anciens comparée à celles des modernes, p. 34-35.

${ }^{11}$ CONSTANT, De La liberté des anciens comparée à celles des modernes, p. 36.

${ }^{12}$ Cf. CALLOT, La pensée liberale au XIX siècle - à travers trois moments de sa formation.

13 Apud CALLOT, La pensée liberale au XIX siècle...., p. 22.
} 
individualista. "[...] sua teorização rica e pensada marcou dois pontos decisivos. Primeiro, a vindicação da liberdade moderna e, segundo, a limitação institucional da autoridade." 14

Escrevendo ainda sob o impacto dos acontecimentos da Revolução Francesa, em especial o período do Terror durante a república jacobina, a preocupação de Constant é com os perigos representados pela ideia de uma soberania popular absoluta. Em consonância com Rousseau, Constant não discorda que o fundamento do poder reside na soberania do povo, porém, a crítica que dirige ao filósofo genebrino é a ausência, em sua obra, de limites para a extensão dessa autoridade. ${ }^{15}$ Daí a defesa de Constant de um governo representativo limitado, de forma a garantir as liberdades individuais. "É a partir do indivíduo e relativamente a ele que deve-se conceber toda a organização da sociedade, é para o cidadão que o Estado deve existir", ressalta Callot. ${ }^{16}$

Deve-se salientar que Constant, ao final do seu discurso, faz a seguinte ressalva: não se deve renunciar às duas espécies de liberdade sobre as quais ele havia discorrido - a individual e a política -, mas dirigir os esforços para combiná-las. "O perigo da liberdade moderna é que, absorvidos no gozo de nossa independência privada, e na busca de nossos interesses particulares, nós renunciemos facilmente a nosso direito de partilha do poder político", alerta. ${ }^{17}$ Nesse sentido, Constant observa que as instituições políticas do país devem, sempre respeitando os direitos particulares dos cidadãos e tendo o cuidado de não atrapalhá-los em suas ocupações privadas, completar a sua educação moral, fazendo com que eles exerçam influência sobre os negócios públicos, seja por meio do voto, seja por meio de suas determinações, de modo a assegurar-lhes um direito de controle e vigilância através da manifestação de suas opiniões.

Outro pensador fundamental do liberalismo do século XIX, o filósofo inglês John Stuart Mill (1806-1873) apresenta no seu famoso ensaio Sobre a liberdade uma definição de liberdade que se aproxima muito da concepção de Constant, calcada na independência pessoal. Para Mill, a liberdade humana compreende três dimensões: a primeira, a da liberdade de consciência, no seu sentido mais amplo, que abrange a liberdade de pensamento e de sentimento e a liberdade de opinião; a segunda, a liberdade de gosto e de inclinações, o que significa que as pessoas são livres para conduzir suas vidas da forma que quiserem, desde que não causem danos a outrem; e, a terceira, a liberdade de união com outros indivíduos, para qualquer propósito, desde que, também, outras pessoas não venham a ser prejudicadas. ${ }^{18}$

Em resumo, como Mill estabelece logo em seguida no ensaio, "a única liberdade que merece esse nome é a de perseguir o nosso próprio bem de nossa própria maneira". Mill completa seu raciocínio, no entanto, tendo o cuidado de acrescentar que essa tarefa de alcançar o nosso próprio bem deve ser empreendida de forma a "não tentarmos privar os outros da sua liberdade, ou

\footnotetext{
${ }^{14}$ MERQUIOR, O liberalismo - antigo e moderno, p. 116.

${ }^{15}$ Nesse sentido, ver MERQUIOR (2014), CALLOT (1987) e CAPALDI (2007).

${ }^{16}$ CALLOT, La pensée liberale au XIX siècle - à travers trois moments de sa formation, p. 22.

${ }^{17}$ CONSTANT, De la liberté des anciens comparée à celles des modernes, p. 46.

${ }^{18}$ Cf. MILL, Sobre a liberdade.
} 
obstruirmos seus esforços para obtê-la". ${ }^{19}$ Ou seja, sobre tudo aquilo que diz respeito apenas a si próprio, o indivíduo tem a mais absoluta soberania. Perante a sociedade, ele só se obriga nas situações que envolverem outras pessoas.

Sobre a liberdade, como atesta Merquior, foi interpretado como um manifesto do individualismo. ${ }^{20}$ Ao enfatizar que a liberdade, como se destacou acima, consiste em "perseguir o nosso próprio bem de nossa própria maneira", Mill enxerga a liberdade como essencial ao autodesenvolvimento do indivíduo. "Uma individualidade desimpedida e uma esfera abrangente de privacidade são necessárias à cultura da personalidade", salienta Merquior, ${ }^{21}$ destacando o caráter instrumental que a liberdade assume nessa perspectiva de Mill, em sintonia com sua visão utilitarista. "Seu objetivo, como um liberal utilitarista [...] consistia em proporcionar à liberdade um lugar central em utilidade, demonstrando seu papel-chave na felicidade e na formação do caráter." 22

A ênfase na individualidade humana, e na liberdade como meio para o cultivo de si, afasta Mill, no entanto, da concepção utilitarista do seu predecessor Jeremy Bentham, que reduz a felicidade a um cálculo meramente quantitativo, com base na intensidade dos prazeres e na ausência de dor. "[...] ao afirmar a importância do desenvolvimento de si, ele identifica o bem-estar do indivíduo a uma sorte completamente diferente da concepção de felicidade de Bentham, o que o conduziu a conclusões que são muito distintas da geração anterior", comenta Simões. ${ }^{23}$ O cultivo da individualidade, por meio do exercício da liberdade, torna-se em Mill também sinônimo de desenvolvimento da autonomia humana, na medida em que o autor define a autonomia como liberdade de escolha, ${ }^{24}$ a possibilidade de fazer escolhas ao nosso próprio modo.

As faculdades humanas da percepção, do julgamento, do sentimento discriminativo e mesmo da preferência moral só podem ser exercidas quando se faz uma escolha. Aquele que faz algo só porque assim é o costume, não faz uma escolha. Ele não

\footnotetext{
${ }^{19}$ MILL, Sobre a liberdade, p. 53.

${ }^{20}$ Cf. MERQUIOR, O liberalismo - antigo e moderno, p. 129.

${ }^{21}$ MERQUIOR, O liberalismo...., p. 129.

22 MERQUIOR, O liberalismo...., p. 129-130.

${ }^{23}$ SIMÕES, “John Stuart Mill: utilitarismo e liberalismo”, p. 178. Em relação à concepção hedonista de Bentham baseada em cálculos essencialmente quantitativos para medir o grau de felicidade, levando em conta apenas a intensidade e a duração dos prazeres, Mill inova quando amplia a noção de felicidade, ao introduzir um elemento qualitativo, chamando a atenção para a qualidade dos prazeres - assim, os prazeres associados às atividades intelectuais, que contribuem para o cultivo da individualidade que Mill destaca em Sobre a liberdade, surgem como superiores e mais desejáveis aos prazeres meramente físicos. É célebre o trecho do $2^{\circ}$ capítulo de Utilitarismo, em que o filósofo inglês afirma: "É melhor ser um ser humano insatisfeito do que um porco satisfeito, é melhor ser um Sócrates insatisfeito do que um tolo satisfeito. Caso o tolo ou o porco forem de opinião diferente, é porque conhecem apenas seu próprio lado da questão. A outra parte conhece os dois lados para fazer a comparação" (MILL, O utilitarismo, p. 33).

24 Neste sentido, ver SIMÕES, "Paternalism and antipaternalism", p.67-68.
} 
aumenta a sua prática, seja para discernir seja para desejar o que é o melhor. O mental e o moral, tal como os poderes dos músculos, são aprimorados apenas quando usados. 25

Ao longo de Sobre a liberdade, o esforço de Mill consiste em estabelecer a fronteira nem sempre tão visível que separa a liberdade do indivíduo dos seus deveres para com a sociedade. No conflito que eventualmente possa existir entre essas duas partes, fica evidente que a preocupação de Mill é, sobretudo, apontar as garantias em favor do indivíduo, indicando a natureza e os limites do poder que pode ser exercido legitimamente pela sociedade sobre ele. ${ }^{26}$

Diferentemente de Constant, Mill não estabelece uma oposição tão nítida entre a liberdade dos antigos (entendida como a liberdade dos cidadãos como membros do corpo coletivo) e a liberdade dos modernos (compreendida como a liberdade individual). Na sua visão, a concepção de liberdade sempre foi a mesma, ${ }^{27}$ desde a Grécia e a Roma antigas até a Inglaterra moderna: a liberdade de não ser oprimido. Só que, se nos tempos antigos, liberdade significava proteção contra a tirania dos dirigentes políticos, nos tempos modernos, pelo menos em muitos países europeus, ela exigia não só as salvaguardas contra o despotismo do Estado, mas também contra a opressão advinda da própria sociedade.

O filósofo inglês descreve o percurso histórico dessa luta pela liberdade, começando pelo estabelecimento de limites ao poder dos governantes, pelo reconhecimento de certas imunidades, chamadas de liberdades políticas ou direitos, cuja infração por parte dos governantes era vista como a violação de um dever, até o posterior estabelecimento de controles constitucionais. Mas à medida que os abusos dos governantes puderam ser evitados por meio dessa série de controles implementada ao longo dos séculos e que os dirigentes políticos deixavam de ser vistos como opositores aos interesses do povo, para assumirem o papel de seus representantes, uma nova

\footnotetext{
${ }^{25}$ MILL, Sobre a liberdade, p. 117. O peso que a individualidade alcança na obra de Mill, a ponto de figurar como um fim em si mesmo, parece se contrapor à sua defesa do utilitarismo. Entretanto, deve-se levar em conta o sentido mais ampliado de utilitarismo que o autor explicita no capítulo introdutório de Sobre a liberdade: "Vejo a utilidade como o tribunal final em todas as questões éticas, mas ela deve ser utilidade em seu sentido mais amplo, firmada nos interesses do homem enquanto um ser que progride" (MILL, Sobre a liberdade, p. 51) - a palavra "progresso" aqui sendo claramente equacionada ao autodesenvolvimento individual para o qual a liberdade é um instrumento fundamental, como ele preconiza ao longo da obra. Nesse sentido, ver também o já citado artigo de SIMÕES, "John Stuart Mill: utilitarismo e liberalismo", no qual o autor postula que o utilitarismo e a defesa da liberdade em Mill são plenamente compatíveis.

${ }^{26}$ Cf. MILL, Sobre a liberdade.

${ }^{27}$ Entretanto, no capítulo introdutório de Sobre a liberdade, Mill esclarece que o tema do seu ensaio é a "Liberdade Civil ou Social", relacionada à natureza e aos limites do poder que pode ser exercido legitimamente pela sociedade sobre o indivíduo e que ele distingue da "assim chamada Liberdade da Vontade, contraposta de modo tão infeliz à incorretamente denominada doutrina da Necessidade Filosófica" (MILL, Sobre a liberdade, p. 37).
} 
ameaça à liberdade surgiu no horizonte. E se o povo passasse a abusar do seu próprio poder? Mill alerta para o perigo da "tirania da maioria" (um tema que, como visto acima, embora não elaborado nestes termos, já aparece em Constant, quando alerta para os perigos de uma soberania popular absoluta. E que também, como veremos adiante, é desenvolvido por Tocqueville):

[...] a vontade do povo significa praticamente a vontade da parte mais numerosa ou da mais ativa do povo; a maioria, ou aqueles que conseguem fazer se passar por ela; o povo, por conseguinte, pode desejar oprimir uma parte de sua totalidade, e são necessárias precauções contra isso tanto quanto contra qualquer tipo de abuso do poder. 28

Para Mill, as relações da sociedade com o indivíduo devem ser estabelecidas de forma tal que a primeira só possa interferir na liberdade de ação do segundo quando se tratar da proteção dela própria, prevenindo danos aos demais membros que a compõem. Mesmo que em nome do bem do próprio indivíduo, qualquer interferência da coletividade em sua liberdade, se for contra a sua vontade, é ilegítima. "Ele [o indivíduo] não pode ser compelido a fazer ou a deixar de fazer algo porque isso seria melhor para ele, ou porque iria fazê-lo mais feliz ou porque, na opinião dos outros, isso seria o melhor ou mesmo o correto", sublinha Mill..$^{29}$

Mill reconhece que a vida em sociedade exige que cada qual seja obrigado a observar uma linha de conduta para com os outros. Essa conduta, conforme ele, requer do indivíduo atenção para não ferir interesses e direitos de terceiros e disposição de suportar sua própria cota de sacrifício e esforços para evitar que a sociedade ou seus membros sofram "danos e inconvenientes". Mas onde começa a soberania do indivíduo e termina a autoridade da sociedade e vice-versa? O filósofo dá a seguinte resposta: "À individualidade deve pertencer a parte da vida em que o indivíduo está interessado, e à sociedade, a parte que interessa principalmente a sociedade". ${ }^{30}$

Na prática, certamente é uma fronteira difícil de estabelecer, mas Mill se esforça em estender o quanto pode o leque de ação do indivíduo. Sua defesa da diversidade e da pluralidade humana passa por conceder aos indivíduos a mais ampla liberdade de pensamento e opinião e a faculdade de levar a sua existência do jeito que quiserem, não porque esta escolha seja a mais indicada, mas porque, se uma "pessoa qualquer possui qualquer soma tolerável de senso comum e experiência, o seu próprio modo de abordar a existência é o melhor, não porque é o melhor em si mesmo, mas porque é o seu próprio modo". ${ }^{31}$ A própria humanidade se enriquece com essa diversidade de opiniões e condutas. "Assim como é útil que enquanto a humanidade for imperfeita haja diferentes opiniões, assim também devem ser diferentes as

${ }^{28}$ MILL, Sobre a liberdade, p. 41, grifo do autor.

${ }^{29}$ MILL, Sobre a liberdade, p. 49.

${ }^{30}$ MILL, Sobre a liberdade, p. 141.

${ }^{31}$ MILL, Sobre a liberdade, p. 131. 
experiências da vida; que deva ser dado livre raio de ação às personalidades variadas." $32 \mathrm{O}$ limite deve ser sempre o cuidado de não provocar danos aos outros, não agir de maneira a tornar a si mesmo um problema para as outras pessoas.

$\mathrm{Na}$ última parte do seu Ensaio sobre a liberdade, Mill faz algumas rápidas observações sobre os limites da autoridade governamental sobre os indivíduos, lembrando aos leitores que o objetivo de seu texto não era tratar desse assunto, mas do controle social sobre os particulares. Limita-se a defender a livre-iniciativa nos assuntos econômicos e a participação popular em instituições como o júri (desde que não seja para casos políticos) e em outras de nível municipal, além de associações voluntárias para fins de filantropia. Para Mill, essas experiências podem funcionar como uma verdadeira "educação política", retirando os indivíduos do estrito círculo dos "egoísmos privados" e acostumando-os à gerência dos negócios em comum, salientando em seguida que a "liberdade política", para se assentar, deve se se fundamentar sobre uma base suficiente de liberdades locais. ${ }^{33}$ A respeito deste último tópico, embora não o desenvolva, Mill apresenta aproximações com o pensamento de Tocqueville (de quem foi amigo próximo), conforme veremos a seguir.

Alexis de Tocqueville (1805-1859), como dissemos, manteve uma amizade estreita com Mill. A longa correspondência que trocaram ao longo de décadas, mais a maneira calorosa com que recebiam os livros e artigos um do outro demonstra a afinidade entre ambos. Mill foi um dos primeiros a publicar dois artigos entusiasmados sobre $A$ democracia na América, na London and Westminter Review, e Tocqueville lhe escreveu, agradecido, dizendo que ele fora o único que o havia "inteiramente compreendido". ${ }^{34}$ Quanto a Constant, Lamberti comenta que a curiosa ausência de qualquer menção desse grande nome do liberalismo na obra tocquevilleana talvez encontre explicação em um certo pudor de Tocqueville em expor os seus desacordos com Constant, em tão grande número quanto as concordâncias entre os dois. ${ }^{35}$

É certo que, como Constant e Mill, Tocqueville foi um ardoroso defensor da liberdade individual. Fiel às suas origens aristocráticas, seu amor pela liberdade residia na sua orgulhosa afirmação da independência individual e no desprezo por qualquer forma de servilismo. Conforme observa Reis, a primeira característica inerente à ideia tocquevilleana de liberdade é a independência - um elemento presente tanto na liberdade "aristocrática" quanto na "democrática", conforme as distinções que Tocqueville vai estabelecendo ao longo de $A$ democracia na América. Mas se, na sociedade aristocrática, a liberdade é privilégio de poucos, na democracia, ela é um direito comum a todos os indivíduos, fortalecendo a convicção de que cada um deve autodeterminar-se em tudo que diz respeito a si mesmo. ${ }^{36}$

\footnotetext{
32 MILL, Sobre a liberdade, p. 114.

${ }^{33}$ MILL, Sobre a liberdade, p. 195.

${ }^{34}$ Cf. TOCQUEVILLE, Ouevres complètes VI. Correspondance anglaise - Correspondance d'Alexis de

Tocqueville avec Henry Reeve et John Stuart Mill, p. 302-303.

${ }^{35}$ Cf. LAMBERTI, Tocqueville et les deux démocraties, p. 76.

${ }^{36}$ Cf. REIS, A liberdade do cidadão: Uma análise do pensamento ético-político de Alexis de Tocqueville, p. 27.
} 
No entanto, a concepção de liberdade de Tocqueville, apesar da relevância que confere à independência individual, não se restringe à perspectiva do liberalismo burguês de Constant, para quem a liberdade é sinônimo de garantia das liberdades privadas, nem tampouco à visão liberalutilitária de Mill, segundo quem, conforme citamos anteriormente, livres são aqueles que podem perseguir o seu próprio bem à sua própria maneira. Como o autor deixa claro em várias passagens de $A$ democracia na América, tendo como exemplo a experiência democrática dos Estados Unidos da primeira metade do século XIX, a verdadeira liberdade combina a independência dos indivíduos com a participação política dos cidadãos.

É justamente por não dissociar liberdade individual da liberdade política que Tocqueville condena o individualismo, diversamente de Constant e Mill. Segundo define Tocqueville no segundo volume de $A$ democracia na América, o individualismo é um fenômeno de origem democrática, produto do processo crescente da igualdade de condições. Na era democrática, conforme aponta, os homens, percebendo-se como iguais e sem vínculos de sujeição uns para com os outros, alimentam tamanho sentimento de independência que "acostumam-se a se considerar sempre isoladamente". ${ }^{37}$ Essa postura individualista, que os leva a afastar-se da massa dos seus semelhantes, para cuidar exclusivamente dos seus interesses privados, acaba provocando duas graves consequências: ela fragiliza a cidadania e, justamente por fazê-lo, torna os indivíduos mais vulneráveis à opressão do Estado e também, paradoxalmente, do poder social, à "tirania da maioria" também temida por Mill.

Segundo Tocqueville, o individualismo esgota "a fonte das virtudes públicas", 38 é como uma doença do espírito público. O individualismo separa o indivíduo do cidadão e leva o primeiro a acreditar que sua liberdade é algo "natural", não o produto de um tipo de sociedade. ${ }^{39}$ Imersas em suas vidas privadas, essas pessoas tendem a negligenciar os assuntos de interesse público, a vê-los como distantes dos seus próprios interesses, abrindo mão da participação política. É com tintas sombrias que Tocqueville descreve essa multidão de indivíduos isolados uns dos outros, que enganosamente se creem livres e independentes:

[...] vejo uma multidão incalculável de homens semelhantes e iguais que giram sem repouso em torno de si mesmos para conseguir pequenos e vulgares prazeres com que enchem sua alma. Cada um deles, retirado à parte, é como que alheio ao destino de todos os outros: seus filhos e seus amigos particulares formam para ele toda a espécie humana; quanto ao resto dos concidadãos, está ao lado deles, mas não os vê; toca-os mas não os sente - cada um só existe em si mesmo e para si

\footnotetext{
${ }^{37}$ TOCQUEVILLE, $A$ democracia na América - Sentimentos e opiniões, p. 121, v. II.

38 TOCQUEVILLE, $A$ democracia na América - Sentimentos e opiniões, p. 121, v. II.

${ }^{39}$ Cf. LAMBERTI, Tocqueville et les deux démocraties.
} 
mesmo e, se ainda lhe resta uma família, podemos dizer pelo menos que pátria ele não tem. ${ }^{40}$

$\mathrm{Na}$ esfera das suas vidas privadas, esses indivíduos acreditam-se independentes tanto material quanto intelectualmente. Mas essa autonomia não passa de uma ilusão, e está sujeita, como dissemos, a duas diferentes formas de despotismo. Uma delas é proveniente do Estado, na forma de um Leviatã-providência que exerce um poder imenso e tutelar sobre uma massa apática de indivíduos fracos e isolados. Aproveitando o vácuo de poder aberto pelos próprios cidadãos, que abdicam da participação política, o Estado se agiganta e toma uma proporção que nem mesmo os tempos antigos conheceram, conseguindo reunir facilmente "todos os poderes públicos" e penetrando "mais habitual e profundamente no círculo dos interesses privados do que qualquer um dos soberanos da Antiguidade foi capaz de fazer". ${ }^{4}$

Esse despotismo que ameaça as democracias modernas, conforme Tocqueville, também se diferencia das tiranias das épocas antigas por ter um caráter mais temperado, degradando os homens "sem os atormentar". $42 \mathrm{O}$ autor o compara a um poder paterno que se esforça para fixar de maneira irreversível os homens na infância. Esse poder não quebra as vontades, mas as amolece, submetendo-as e dirigindo-as; não força ninguém a agir, pelo contrário, cuida para que ninguém o faça; não destrói as iniciativas, mas impede que elas nasçam. "Assim, todos os dias ele torna menos útil e mais raro o emprego do livre-arbítrio; encerra a ação da vontade num espaço menor e defrauda pouco a pouco cada cidadão até mesmo do uso de si." 43

Outro tipo de despotismo que Tocqueville vislumbra relaciona-se ao fenômeno da "tirania da maioria", que o autor analisa a partir de duas perspectivas: a primeira é a onipotência da maioria decorrente de uma vontade popular soberana e a segunda, que interessa realçar aqui, é a "tirania intelectual e espiritual", para usar as palavras de Jasmin, ${ }^{44}$ exercida pela mentalidade dominante da maioria, a qual constrange as liberdades dos indivíduos e a expressão das minorias.

Os indivíduos atomizados que compõem as massas modernas, iludidos pela convicção de que são autônomos e independentes, acabam formando uma mentalidade coletiva homogênea. ${ }^{45}$

40 TOCQUEVILLE, A democracia na América - Sentimentos e opiniões, p. 389, v. II.

${ }^{41}$ TOCQUEVILLE, A democracia na América - Sentimentos e opiniões, p. 388, v. II.

42 TOCQUEVILLE, A democracia na América - Sentimentos e opiniões, p. 388, v. II.

43 TOCQUEVILLE, A democracia na América - Sentimentos e opiniões, p. 390, v. II.

${ }^{44}$ JASMIN, Alexis de Tocqueville - A historiografia como ciência política, p. 65.

45 Mill também alerta para os perigos de uma mentalidade coletiva homogênea no $2^{\circ}$ capítulo de Sobre a liberdade, intitulado "Sobre a liberdade de pensamento e discussão" (MILL, Sobre a liberdade, p. 57-112), embora, diferente de Tocqueville, não faça uma condenação do individualismo. Para Mill, a liberdade de expressão, compreendendo a liberdade de pensamento e discussão, é fundamental para garantir o desenvolvimento do conhecimento humano, porque o silenciamento de uma opinião, por mais minoritária que seja, representa "roubar a raça humana, tanto a posteridade quanto a geração atual". Isso ocorre porque, caso a opinião silenciada esteja correta, a humanidade se vê privada de trocar o erro pela verdade e, caso 
Essa mentalidade coletiva homogênea de que fala Tocqueville é, por sua vez, produto do que Ros define como um "estranho vínculo entre relativismo e onipotência da massa". ${ }^{4}$ Se o aprofundamento da igualdade entre os cidadãos nos tempos modernos torna-os cada vez menos propensos a crer cegamente em determinado homem ou em determinada classe social, em contrapartida, a disposição para acreditar na massa aumenta.

Nos tempos da igualdade, os homens não têm nenhuma fé nos outros, por causa da sua similitude; mas essa mesma similitude lhes proporciona uma confiança quase ilimitada no juízo do público, porque não lhes parece verossímil que, tendo todos luzes idênticas, a verdade não se encontre na maioria. ${ }^{47}$

Essa disposição para a uniformização do pensamento tem como consequência a repressão daqueles que ousam pensar e se comportar de uma maneira diversa.

Como corrigir os males advindos do individualismo? Tocqueville parece não ter dúvidas: é pelo exercício da própria liberdade. Mas liberdade no sentido tocquevilleano, que compreende, conforme enumera Lamberti, três dimensões: a) a ideia aristocrática da independência, que valoriza a liberdade como um fim em si mesmo. Nessa perspectiva, a liberdade equivale ao sentimento que o indivíduo tem de seu próprio valor; b) a ideia de participação política, que valoriza uma cidadania ativa, pela qual os indivíduos têm efetiva participação nos negócios públicos; e c) a ideia de direitos iguais para todos, uma vez que Tocqueville reconhecia que, nas sociedades democráticas modernas, já não havia mais espaço para um ordenamento social desigual, característico da aristocracia. Essas três dimensões formam uma síntese em que a liberdade é vista não só como um direito do indivíduo, mas também como um dever: dever para consigo mesmo, para com o próximo e para com a comunidade em geral. A liberdade é tanto um dever moral quanto cívico.48

Com base naquilo que testemunhou durante a sua viagem pelos Estados Unidos, Tocqueville pôde perceber que a democracia norte-americana desenvolveu mecanismos internos para refrear as ameaças provenientes tanto do despotismo do Estado quanto do oriundo da sociedade. Entre esses elementos, além da forma federativa do Estado e da autonomia do Poder Judiciário e os próprios costumes dos norte-americanos, ele enumera o poder comunal, a liberdade

estiver errada, os seres humanos também perdem a chance de "ter uma percepção mais clara e vívida da verdade, produzida da colisão desta com o erro, um benefício tão grande quanto o primeiro" (MILL, Sobre a liberdade, p. 23). Páginas à frente, o pensador inglês alerta que a imposição de uma opinião dominante, sufocando as opiniões dissidentes, resulta em uma "pacificação intelectual" que tem por consequência o sacrifício de "toda a coragem moral da mente humana", levando os seres humanos ao conformismo e ao servilismo (MILL, Sobre a liberdade, p. 81).

${ }^{46}$ ROS, Los dilemas de la democracia liberal-Sociedade civil y democracia em Tocqueville, p. 60.

47 TOCQUEVILLE, A democracia na América - Sentimentos e opiniões, p. 11, v. II.

${ }^{48}$ Cf. LAMBERTI, Tocqueville et les deux démocraties. 
de associação e a liberdade de imprensa. Para os propósitos deste texto, nos limitaremos a discutir, no tópico seguinte, suas ideias sobre o poder comunal, situando-as dentro do debate sobre liberdade e territorialidade e confrontando-as com as opiniões de Constant e Mill.

\section{Liberdade $\mathrm{x}$ territorialidade}

No seu já citado discurso Da liberdade dos antigos comparada à dos modernos, Benjamin Constant afirma que a oposição, que ele estabelece, entre as repúblicas antigas, que privilegiavam a soberania do corpo social, e as modernas, com sua ênfase nas liberdades individuais, tem sua origem numa diferença essencial. Essa diferença reside na extensão territorial. Ao passo que as repúblicas antigas eram fechadas em limites estreitos, onde "o republicano mais obscuro de Roma ou Esparta era uma autoridade", no mundo moderno - "onde os menores Estados são incomparavelmente mais vastos que Esparta ou Roma durante cinco séculos" 49 -, a influência pessoal de cada indivíduo, em meio à multidão, se torna um elemento imperceptível da vontade social.

O cotidiano dessas pequenas repúblicas da Antiguidade, sempre em estado de guerra umas contra as outras, conforme descreve Constant, era marcado pelo "exercício contínuo dos direitos políticos, a discussão diária dos negócios do Estado". Sem essas agitações, ressalta Constant, os povos livres daquela época ter-se-iam entediado, "sob o peso de uma ociosidade dolorosa". Mas esse mesmo ardor cívico que imperava entre os povos antigos, Constant acredita que acarretaria apenas "perturbação e cansaço" às nações modernas, nas quais o comércio veio em substituição à guerra e "onde cada indivíduo, ocupado por suas especulações, por seus empreendimentos, pelos resultados que obtém ou espera, quer ser desviado disso o menos possível". 50

Em Sobre a liberdade, Mill escreve, em sintonia com Constant, que uma característica das pequenas repúblicas da Antiguidade era a preocupação em "regular toda e qualquer parte da conduta privada a partir da autoridade pública", sob a alegação de que o Estado "tem um profundo interesse na disciplina mental e física de cada um de seus cidadãos". Para o pensador inglês, esse esforço era justificável, na medida em que essas pequenas repúblicas, por viverem num estado permanente de guerra, não podiam se permitir ao luxo de dar-se um período, por diminuto que fosse, de descanso em termos de energia e comando, sob o risco de essa trégua acabar-lhes sendo fatal para a sua própria independência. Já no mundo moderno, o tamanho maior das comunidades políticas, além da separação entre o poder temporal e espiritual, preveniu, segundo ele, "uma maior interferência da lei nos detalhes da vida privada". ${ }^{51}$

Como se vê, tanto Constant quanto Mill estabelecem uma conexão entre liberdade individual e extensão territorial das comunidades políticas: as pequenas dimensões das repúblicas

\footnotetext{
${ }^{49}$ CONSTANT, De La liberté des anciens comparée à celles des modernes, p. 22.

${ }^{50}$ CONSTANT, De La liberté des anciens comparée à celles des modernes, p. 25.

${ }^{51}$ MILL, Sobre a liberdade, p. 54.
} 
antigas surgem como um dos fatores que acarretam um maior controle social e político sobre os indivíduos, enquanto a maior extensão territorial das nações modernas, também muito mais populosas, contribui para que os indivíduos desfrutem de mais independência em suas vidas privadas, embora Constant reconheça que a influência pessoal dos cidadãos nos assuntos públicos tenha se reduzido enormemente na modernidade, em comparação com os povos da Antiguidade.

Tocqueville, por seu turno, até concede que as grandes nações permitem um maior florescimento do "egoísmo individual" e que elas podem realizar progressos mais rápidos que os pequenos Estados, uma vez que suas metrópoles funcionam como vastos centros intelectuais que atraem gente de todos os lugares e onde "vêm resplandecer e se combinar todos os raios do espírito humano". ${ }^{52}$ Mas, fiel à sua concepção de liberdade, que não separa a liberdade individual ("moderna") da liberdade política ("antiga"), ele não está tão convencido assim de que a grandeza das nações modernas favoreça a independência pessoal.

Como Constant, Tocqueville admite que, nas sociedades democráticas modernas, os indivíduos não só não dispõem de tempo para se imiscuir nos assuntos de interesse público, como até perderam o gosto por tal tarefa. "A vida privada é tão ativa nos tempos democráticos, tão agitada, tão cheia de desejos, de trabalhos, que quase não resta mais energia nem tempo para a vida política de cada homem." 53 Mas ele está longe de ver isso como uma dádiva, diferente de Constant, com sua visão "hedonista" da liberdade, reduzindo-a a um instrumento a serviço de uma concepção materialista da felicidade, como o censurava Chateaubriand. ${ }^{54}$

Para Tocqueville, justamente por se afastarem da política que os cidadãos das modernas nações europeias permitem o desenvolvimento do que ele julga ser um dos piores males da cena pública: a centralização do poder em todas as suas esferas. Essa excessiva centralização afeta diretamente a independência pessoal dos indivíduos, tanto na esfera pública quanto na privada. "Em toda a parte o Estado tende cada vez mais a dirigir por si mesmo os menores cidadãos e a conduzir sozinho cada um deles nos menores negócios." 55

É importante ressaltar aqui que a centralização criticada por Tocqueville é a administrativa, uma vez que ele considera ser de suma importância, para a prosperidade das nações, que elas estejam submetidas a um forte poder central governamental. A este poder cabe cuidar dos interesses que sejam comuns a toda a nação, como as leis gerais e as relações com os estrangeiros. Um poder administrativo centralizado é aquele que se ocupa também em coordenar os interesses específicos de certas partes das nações, como os empreendimentos comunais. 56

Falando das grandes nações modernas da Europa, mas tendo em vista particularmente o exemplo da França, Tocqueville considera que o sistema representativo - que Constant julga

\footnotetext{
52 TOCQUEVILLE, $A$ democracia na América - Leis e costumes, p. 180-181, v. I.

53 TOCQUEVILLE, $A$ democracia na América - Sentimentos e opiniões, p. 283, v. II.

${ }^{54}$ Cf. LAMBERTI, Tocqueville et les deux démocraties.

55 TOCQUEVILLE, A democracia na América - Sentimentos e opiniões, p. 376, v. II.

${ }^{56}$ Cf. TOCQUEVILLE, $A$ democracia na América - Leis e costumes, p. 98, v. I.
} 
suficiente para assegurar a liberdade política dos cidadãos nos tempos modernos -, embora diminua o mal que a extrema centralização administrativa possa produzir, não é suficiente para destruí-lo. Interferindo na cena pública apenas para escolher, pelo voto, seus representantes, mas abdicando de uma participação mais efetiva nos assuntos de interesse comum de suas comunidades locais, os indivíduos tornam-se sujeitos a um poder central que interfere o todo tempo em seu cotidiano. Essa sujeição acaba degradando-os, tanto na qualidade de cidadãos quanto na qualidade de indivíduos livres e autônomos.

A sujeição nos pequenos assuntos se manifesta todos os dias e faz sentir indistintamente em todos os cidadãos. Ela não os desespera, mas os contraria sem cessar e leva-os a renunciar ao uso de sua vontade. [...] É inútil encarregar esses mesmos cidadãos, que foram tomados tão dependentes do poder central, de escolher de vez em quando os representantes desse poder; esse uso tão importante, mas tão curto e tão raro, de seu livre-arbítrio, não impedirá que percam pouco a pouco a faculdade de pensar, de sentir e de agir por si mesmos e que caiam assim gradualmente abaixo do nível da humanidade. ${ }^{57}$

Mais uma vez é no exemplo dos Estados Unidos que Tocqueville extrairá um modelo que combinará centralização governamental com descentralização administrativa, reunindo as vantagens de uma grande nação, como a força e o poderio, com as virtudes das pequenas repúblicas, que sempre foram "o berço da liberdade política", como ele escreve no primeiro volume de $A$ democracia na América. ${ }^{58}$ Esse modelo consiste no sistema federativo adotado nos EUA, em que a União conserva o poder governamental descrito anteriormente, cuidando das leis gerais e das relações com outras nações, e, dentro das fronteiras do território norte-americano, o poder é pulverizado entre os estados e as comunas.

Porém, é sobretudo nas comunas que Tocqueville louva o exercício efetivo da liberdade política por parte dos cidadãos. Como diz Boesche, foi nas comunas da Nova Inglaterra (as townships) que Tocqueville pôde testemunhar, quando fez seu périplo pelo país no início da década de 1830, as assembleias dos cidadãos discutindo os interesses em comum, um retrato que the evocou a praça pública da Atenas democrática. ${ }^{9}$ "Na comuna da Nova Inglaterra, a lei da representação não é admitida. É na praça pública e no seio da assembleia geral dos cidadãos que se tratam, como em Atenas, os assuntos concernentes ao interesse de todos", anota Tocqueville. ${ }^{60}$ Permanecendo como corpo independente em tudo aquilo que diz respeito somente a ela, a comuna é onde o povo exerce sua soberania da forma mais direta. "O habitante da Nova Inglaterra apega-se

\footnotetext{
57 TOCQUEVILLE, A democracia na América - Sentimentos e opiniões, p. 392, v. II.

58 TOCQUEVILLE, $A$ democracia na América - Leis e costumes, p. 179, v. I.

${ }^{59}$ BOESCHE, The strange liberalism of Alexis de Tocqueville, p. 120.

${ }^{60}$ TOCQUEVILLE, A democracia na América - Leis e costumes, p. 48-49, v. I.
} 
à sua comuna não tanto porque nasceu nela, mas porque vê nessa comuna uma corporação livre e forte de que faz parte e que vale a pena procurar dirigir", observa Tocqueville. ${ }^{61}$

Tocqueville observa que a liberdade comunal nos Estados Unidos é uma experiência anterior à própria independência do país. Na Nova Inglaterra, ela já estava completamente estabelecida desde 1650. "As colônias ainda reconhecem a supremacia da metrópole; a monarquia é a lei do Estado, mas já a república está toda vida na comuna", sublinha. Para ele, é na independência comunal - e não nos estados e na União - que se assentam "o princípio e a vida da liberdade americana". ${ }^{62}$

A comuna funciona como um contraponto às ameaças de centralização do poder, constituindo-se como um obstáculo ao despotismo do Estado, como também é uma barreira à outra forma de despotismo que também assombra as democracias modernas, segundo Tocqueville, conforme já apontamos: a tirania da maioria. Com relação ao poder central, Tocqueville diz que as comunas podem ser equiparadas a um indivíduo livre, que "em tudo que diz respeito aos deveres mútuos dos cidadãos [neste caso, os deveres para com a nação], tornou-se súdito [...]. Em tudo que diz respeito a si mesmo, permaneceu senhor". ${ }^{63}$

Apesar de reconhecer que, nas grandes nações, por conta da grande diversidade de interesses, é mais difícil formar uma maioria compacta, o autor alerta que, "numa grande república, as paixões políticas tornam-se irresistíveis, não apenas porque o objeto que elas perseguem é imenso, mas também porque milhões de homens as sentem da mesma maneira e no mesmo momento". ${ }^{64}$ É justamente contra essa vontade nacional que o poder comunal serve de anteparo.

Quando ordena soberanamente, o governo central que a representa [a vontade nacional] deve remeter-se, para a execução de seu comando, a agentes que muitas vezes não dependem dele e que ele não pode dirigir a cada instante. Os corpos municipais e as administrações dos condados constituem, pois, como que obstáculos ocultos, a retardar e a dividir o fluxo da vontade popular. ${ }^{65}$

Conforme já demonstramos, Tocquevile aponta, em várias passagens dos dois volumes de A democracia na América, que a mentalidade homogênea que ele via se estabelecer nas democracias modernas é fruto do isolamento dos cidadãos, imerso nos seus interesses privados. Ao passo que, exercendo sua liberdade política, os indivíduos são incentivados a expressar as suas vozes em público, não se acomodando a uma "vontade nacional", fruto do imaginário coletivo - e dessa forma a pluralidade é manifestada. É de se questionar, no entanto, se, no interior das comunas, as

\footnotetext{
61 TOCQUEVILLE, $A$ democracia na América - Leis e costumes, p. 78, v. I.

62 TOCQUEVILLE, $A$ democracia na América - Leis e costumes, p. 78, v. I.

63 TOCQUEVILLE, $A$ democracia na América-Leis e costumes, p. 75-76, v. I.

64 TOCQUEVILLE, $A$ democracia na América - Leis e costumes, p. 180, v. I.

65 TOCQUEVILLE, A democracia na América - Leis e costumes, p. 308, v. I.
} 
maiorias locais que se formam também não poderiam se tornar "tiranas", lançando mão do controle social das repúblicas da Antiguidade que tanto Mill quanto Constant deploram.

Tocqueville admite que, nos Estados Unidos da primeira metade do século XIX, havia de fato uma mentalidade uniforme que deixava pouco espaço para os espíritos livres e discordantes, mas essa mentalidade era muito mais consequência dos rígidos costumes dos próprios norteamericanos do que do seu modelo político. Além do mais, outros mecanismos da constituição política e social dos Estados Unidos - como a própria alternância de poder nas comunas, com suas eleições anuais; a ampla liberdade de associação e de imprensa, e o Poder Judiciário, já mencionados e que não serão tratados neste texto - também serviam de obstáculos à opressão dos indivíduos pela sociedade.

Para Tocqueville, a liberdade comunal é algo "raro e frágil" e, entre todas as liberdades, a das comunas é a que está mais exposta às invasões do poder central. Entregues a si mesmas, as instituições comunais não são capazes de lutar contra um poder empreendedor e forte. Por isso, se a liberdade comunal não estiver arraigada nos costumes, é muito fácil destruí-la. "E ela só pode se arraigar nos costumes depois de haver subsistido por muito tempo nas leis", reitera Tocqueville. 66

No entanto, na opinião de Tocqueville, é na comuna que reside a força dos povos livres. As instituições comunais, segundo ele, funcionam como escolas primárias, que ensinam aos indivíduos o exercício da cidadania e fazem com que eles tomem gosto pela liberdade política. Para concluir com o autor:

Sem instituições comunais uma nação pode se dotar de um governo livre, mas não possui o espírito da liberdade. Paixões passageiras, interesses de um momento, o acaso das circunstâncias podem lhe dar as forças externas da independência; mas o despotismo reprimido no interior do corpo social cedo ou tarde volta à tona. ${ }^{67}$

\section{FREEDOM AND TERRITORIALITY: THE LIMITS OF POWER OF THE STATE AND SOCIETY IN CONSTANT, MILL AND TOCQUEVILLE}

Abstract: Benjamin Constant, John Stuart Mill and Alexis de Tocqueville were three great names in nineteenth-century liberalism, recognized by the relevance of their reflections on freedom. The aim of the article is to discuss the conception of freedom in these three authors - based on the relation they establish between individual freedom and political freedom and the territorial extension of political communities - and the limits of the power of the State and society over individuals. To this end, the perspective of Constant and Mill, who conceives freedom in modern times as synonymous with individual freedoms, will be confronted with that of Tocqueville, whose conception of freedom combines individual independence with political participation. Concerning territoriality, our effort will be

\footnotetext{
66 TOCQUEVILLE, $A$ democracia na América - Leis e costumes, p. 71, v. I.

67 TOCQUEVILLE, $A$ democracia na América - Leis e costumes, p. 71, v. I.
} 
to show that, while for Constant and Mill, the greater extension of modern states is a factor favoring individual freedom - as opposed to the narrow limits of the ancient republics, which exercised greater control over the citizens - for Tocqueville, it is precisely the communal power, represented by municipal bodies or communes, that gives citizens the chance to have greater political participation. Keywords: freedom - territoriality - politics - liberalism.

\section{Referências bibliográficas:}

BOESCHE, Roger. The strange liberalism of Alexis de Tocqueville. London: Cornell University Press, 1987.

CALLOT, Emile-François. La pensée liberale au XIX siècle - à travers trois moments de sa formation. Paris: L'Hermès, 1987.

CONSTANT, Benjamin. De la liberté des anciens comparée à celles des modernes. [1819]. Paris: Berg International, 2016.

JASMIN, Marcelo Gantus. Alexis de Tocqueville - A historiografia como ciência política. Rio de Janeiro: Access Editora, 1997.

LAMBERTI, Jean-Claude. Tocqueville et les deux démocraties. Paris: PUF, 1983.

MERQUIOR, José Guilherme. O liberalismo - antigo e moderno. 3. ed. ampl. São Paulo: É Realizações Editora, 2014.

MILL, Sobre a liberdade. São Paulo: Editora Hedra, 2011.

O utilitarismo. São Paulo: Iluminuras, 2000.

ROS, Juan Manuel. Los dilemas de la democracia liberal - Sociedade civil y democracia em Tocqueville. Barcelona: Editorial Crítica, 2001.

REIS, Helena Esser dos. A liberdade do cidadão: Uma análise do pensamento ético-político de Alexis de Tocqueville. 2002. Tese (Doutorado em Filosofia) - Faculdade de Filosofia, Letras e Ciências Humanas da Universidade de São Paulo, São Paulo, 2002.

SIMÕES, Mauro Cardoso. Paternalism and antipaternalism. Ethic@, Florianópolis, v. 10, n. 1, p. 65-83, jun. 2011.

John Stuart Mill: utilitarismo e liberalismo. Veritas, Porto Alegre, v. 58, n. 1, p. 174-189, jan./abril 2013. 
TOCQUEVILLE, Alexis de. A democracia na América - Leis e costumes. São Paulo: Martins Fontes, 1998.v. 1.

A democracia na América - Sentimentos e opiniões. São Paulo: Martins Fontes, 2000.v. 2.

- Oeuvres complètes VI. Correspondance anglaise - Correspondance d'Alexis de Tocqueville avec Henry Reeve et John Stuart Mill. 6 ed. Paris: Gallimard, 1954. 